\title{
AVALIAÇÃO DE INSTITUIÇÕES DA REDE FEDERAL DE EDUCAÇÃO PROFISSIONAL, CIENTÍFICA E TECNOLÓGICA:
}

considerações a partir dos eixos do Sistema Nacional de Avaliação da Educação Superior

\author{
EVALUATION OF INSTITUTIONS OF THE FEDERAL NETWORK OF PROFESSIONAL, \\ SCIENTIFIC, AND TECHNOLOGICAL EDUCATION: \\ considerations based on the axes of the Brazilian System \\ of Evaluation of Higher Education
}

\author{
EVALUACIÓN DE INSTITUCIONES DE LA RED FEDERAL DE EDUCACIÓN \\ PROFESIONAL, CIENTÍFICA Y TECNOLÓGICA: \\ enfoques basados en los ejes del Sistema Brasileño de Evaluación \\ de la Educación Superior
}

\author{
Liz Denize Carvalho Paiva \\ (UFRRJ, Brasil)
}

Nádia Maria Pereira de Souza

(UFRRJ, Brasil)

doi) https://doi.org/10.29404/rtps-v5i8.366

RESUMO: $O$ artigo apresenta uma análise da concepção regulatória do Sistema Nacional de Avaliação da Educação Superior (SINAES) referenciada no Instrumento de Avaliação Institucional Externa que abrange a transformação de organização acadêmica e os procedimentos de recredenciamento de Instituições de Educação Superior (IES). 0 Instrumento atualizado em 2017 se constitui na principal ferramenta que define o Conceito Institucional $(\mathrm{Cl})$ da IES decorrente de pesos atribuídos aos cinco eixos do SINAES. A análise da investigação recaiu sobre os Institutos Federais de Educação, Ciência e Tecnologia, tendo em vista o aumento dos pesos dos eixos "Desenvolvimento Institucional e Infraestrutura" e a diminuição do peso do eixo "Políticas Acadêmicas". 0 estudo de natureza qualitativa contemplou características de pesquisa bibliográfica e documental. Os resultados apontaram para a indução da qualidade focada na gestão burocrática e na meritocracia da avaliação.

Palavras-Chave: Avaliação Institucional, Sistema Nacional de Avaliação da Educação Superior, Instituição Federal de Educação Profissional e Tecnológica.

ABSTRACT: The paper presents an analysis of the regulatory conception of the National Higher Education Assessment System (SINAES) referenced in the External Institutional Assessment Instrument that covers the transformation of academic organization and the re-accreditation procedures of Higher Education Institutions (HEls). The Instrument, updated in 2017, is the main tool that defines the institutional concept (CI) of the HEl due to weights attributed to the five axes of SINAES. The analysis of the investigation fell on the Federal Institute of Education, Science and Technology, with a view to increasing the weights of the Institutional Development and Infrastructure axes and decreasing the weight of the Academic Policies axis. The qualitative study contemplated characteristics of bibliographic and documentary research. The results pointed to the induction of quality focused on bureaucratic management and the meritocracy of the evaluation.

Keywords: Institutional Evaluation, National Higher Education Evaluation System, Federal Institution of Professional and Technological Education.
RESUMEN: El artículo presenta un análisis de la concepción reguladora del Sistema Nacional de Evaluación de la Educación Superior (SINAES) al que se hace referencia en el Instrumento de Evaluación Institucional Externa que cubre la transformación de la organización académica y los procedimientos de reacreditación de las Instituciones de Educación Superior (IES). El Instrumento, actualizado en 2017, es la herramienta principal que define el concepto institucional (IC) de la IES debido a los pesos atribuidos a los cinco ejes del SINAES. El análisis de la investigación recayó en el Instituto Federal de Educación, Ciencia y Tecnología, con miras a aumentar los pesos de los ejes de Desarrollo Institucional e Infraestructura y disminuir el peso del eje de Políticas Académicas. El estudio asumió características de investigación bibliográfica y documental. Los resultados apuntaban a la inducción de calidad centrada en la gestión burocrática y la meritocracia de la evaluación.

Palabras Clave: Evaluación Institucional, Sistema Nacional de Evaluación de la Educación Superior, Institución Federal de Educación Profesional y Tecnológica. 


\section{Introdução}

Para tratarmos da temática avaliação educacional, precisamos primeiramente caracterizar a educação que estamos nos referindo. A educação pautada neste texto se constitui no processo de emancipação humana, quando se faz possível o contato com o conhecimento científico, ressignificando-o diante do contexto vivenciado pelo sujeito em seu cotidiano. O processo de ensino-aprendizagem construído no ambiente escolar que caracteriza a educação formal aponta caminhos aos educandos para a dignidade humana, por meio da apropriação do conhecimento e dos fatos sociais instituídos, definindo a convivência da coletividade.

O fato é, que no sistema capitalista, apesar do amparo legal aos direitos e deveres dos indivíduos, a linha divisória entre dominantes e dominados recai sob o julgo do poder em seus diversos formatos: social, cultural, econômico, religioso, estatal, simbólico, entre outros.

Fazer parte das decisões tomadas em sociedade seja nas esferas micro ou macro de um coletivo, significa que os direitos e deveres que caracterizam um regime democrático estão sendo exercitados. Mas esta conquista para se efetivar plenamente exige o acesso ao conhecimento e à cultura, bem como à participação em sociedade, proporcionando assim, o desenvolvimento da análise, da crítica, da avaliação e da tomada de decisão frente ao instituído.

$\mathrm{O}$ ato de avaliar pressupõe o julgamento de valor sobre um objeto em questão, circundado por paradigmas construídos ao longo do tempo. Os paradigmas segundo Kuhn (1998) se caracterizam pelo conjunto de valores atribuídos aos estudos científicos, reconhecidos universalmente, que por um período determinado, servem de matrizes, nutrindo a base de outras pesquisas.

Considerando tais aspectos, a educação tem sido vista pelo Estado (GRAMSCI, 1988) como uma importante aliada na busca de resultados aos seus objetivos, tanto como fonte de formação de mão de obra em atendimento às demandas do sistema capitalista, como para a inculcação dos valores estabelecidos pela ordem mundial de produtividade e consumo. Nesta lógica, o Estado se constitui em meio às intempéries da sociedade política, representada pelos governantes e pela sociedade civil, aqui considerada diante dos aparelhos privados. As ideologias em questão são identificadas mediante controle, coerção e subordinação aos grupos que não fazem parte do poder hegemônico.

Na contramão deste contexto, Saviani (2017) afirma que a existência do homem se constitui no 'trinômio situação-liberdade-consciência'. Esta tese se ampara no fato do homem agir em sociedade, transformando-a. Estas transformações ocorrem quando as ações humanas, que em geral são realizadas espontaneamente, se deparam com cenários diferentes dos então vivenciados. Estas novas situações pressionam o homem a problematizá-las em busca de soluções, passando assim, da consciência irrefletida e não intencional para a intencionalidade, a reflexão e a sistematização das questões. 
Deste modo, para abordarmos a avaliação institucional neste estudo, utilizamos como recurso teórico e metodológico a pesquisa de natureza qualitativa (MINAYO, 2008), visitando e revisitando autores em suas publicações, bem como recorrendo a documentos e legislações que pudessem contribuir na problemática. Esta se amparou na inquietação por analisar as principais mudanças no Instrumento de Avaliação Externa do Instituto Nacional de Estudos e Pesquisas Educacionais Anísio Teixeira (Inep), órgão do Ministério da Educação (MEC) sob a égide do Sistema Nacional de Avaliação da Educação Superior (SINAES). O mote foi observar os aspectos moventes da avaliação no Instituto Federal de Educação, Ciência e Tecnologia, cujas singularidades originais o colocam em foco.

Assim, referenciadas as questões introdutórias, demos sequência ao texto, destacando os principais paradigmas presentes na avaliação educacional e, por conseguinte, na avaliação institucional das Instituições de Educação Superior. Em seguida, expomos os elementos que compõem o histórico da avaliação institucional sob o viés regulatório refletido no SINAES, além de registrar as concepções formativa (BELLONI, 2000) e sociocrítica (LIBÂNEO, 2013) defendidas por autores progressistas.

Na seção posterior, apresentamos o Instrumento de Avaliação Externa e seus nuances procedimentais e conceituais ao longo do tempo, além dos índices, indicadores e pesos que os compõe. Por fim, analisamos os cenários dos Institutos Federais de Educação, Ciência e Tecnologia (IFs) avaliados pelo instrumental do SINAES no período de 2018 a 2019, sob a tutela do Instrumento atualizado em 2017 e em vigor. Os elementos conclusivos em nossa análise apontaram para a lógica da métrica e do controle da avaliação, referenciada na concepção burocrática e regulatória, em detrimento da concepção formativa e sociocrítica.

\section{A avaliação educacional e seus paradigmas}

A educação formal, inserida no sistema educacional, guarda a liberdade do homem como requisito de sua gênese, mas que por contradição, sofre do referido sistema ações promovidas por mecanismos burocráticos, meritocráticos e de controle, também presentes na avaliação.

Franco (1991) nos auxilia na análise ao apresentar os pressupostos epistemológicos da avaliação educacional expondo a problemática da qualidade da educação no Brasil nos idos dos anos de 1970 e as possíveis causas decorrentes que se asseveraram nas décadas posteriores. Explica que o ponto aventado de longa data, em especial pelos governantes, dirige-se à avaliação como um dos principais agentes a ser implicado na questão. Estudos sistemáticos sobre a temática revelam paradigmas que afetam, sobremaneira, a avaliação, dentre eles, os denominados: objetivista, subjetivista e o vínculo indivíduo-sociedade.

No paradigma objetivista as bases valorizadas correspondem aos expoentes do positivismo quando o reconhecimento acerca da ciência se encontra pautado na operacionalização, nas hipóteses, na experimentação, na quantificação, assim como na 
neutralidade e distanciamento entre pesquisador e objeto investigado. Tal verdade foi transposta para os processos de ensino-aprendizagem, em que o foco se dirige ao controle por meio dos instrumentos aferidores, igualando-se ao modelo de ciência aplicado à natureza física.

Assim, dos testes e instrumentos métricos e padronizados provenientes do paradigma objetivista surgiram correntes de pensadores que passaram a valorizar predominantemente o sujeito, sendo conhecidas como resultantes do novo paradigma emergente, o subjetivismo. Nesta concepção de mundo, há o enfoque do sujeito sobre o objeto pesquisado, interferindo e influenciando diretamente por meio de suas interpretações, valores e experiências. Franco (1991) ressalta as contribuições deste paradigma ao emergir avaliações que valorizavam a construção do pensamento do educando, bem como o desenvolvimento de sua capacidade de autoavaliação, iniciativa e pensamento crítico. Contudo, a autora pontua também, aspectos considerados prejudiciais à educação, como a aversão aos elementos quantitativos tão necessários às pesquisas sociais que juntamente com a subjetividade podem proporcionar o equilíbrio às análises.

Franco (1991) alerta ainda sobre as limitações do paradigma subjetivista, pois como o modelo objetivista, ao impulsionar a radicalização por princípios absolutos não se mostra capaz de interpretar e apresentar soluções para a realidade nodal da educação. Na esteira dos paradigmas apresentados até aqui, um dos elementos que se tornaram restritos em seus modelos diz respeito à negação da história e da relação do sujeito com suas experiências e com a sociedade.

Após alguns resultados com as experiências relatadas, novos esforços foram empreendidos na luta pela compreensão da realidade escolar. Surgiu então a compreensão da importância dos aspectos inerentes ao sujeito e seu processo relacional com o seu entorno, adicionando a história como fator preponderante às experiências já vividas e relatadas, mas especialmente as experiências cotidianas da contemporaneidade. Nesta trilha, passou-se a identificar as dimensões e caminhos da teoria e da prática, formando um movimento contínuo e cíclico, caracterizando assim, a práxis (GAMBOA, 1988).

Este movimento contraditório, que por vezes desvela as fragilidades teóricas frente ao dia a dia se pôs a ser considerado e pesquisado. Neste mote, o indivíduo e seus aspectos relacionais tornam-se ingredientes para a ressignificação do conhecimento, proporcionando elementos para a transformação social. Tal transformação, imbuída do aspecto relacional do paradigma indivíduo-sociedade, pode acompanhar os elementos micro das instituições de ensino, assim como da esfera macro das políticas educacionais. Neste paradigma de abordagem cooperativa, os conhecimentos das múltiplas áreas do conhecimento se complementam e se retroalimentam, gerando novos enfoques da realidade. No âmbito da avaliação, observamos que esta abordagem integra o contexto histórico dos sujeitos e das instituições de ensino, sem deixar de valorizar as identidades e os conhecimentos científicos construídos ao longo da humanidade, desvelando-os e ressignificando-os de acordo com as singularidades sociais (FRANCO, 1991). 
Os fundamentos da totalidade se apresentam aderentes a esta concepção, pois a relação indivíduo-sociedade no processo histórico se mostra dinâmica e contemporânea, envolvendo um movimento dialético presente nas distintas representações e ações da práxis. Conhecer e compreender os objetivos e motivações para a ação da avaliação reflete a consciência crítica social, tão necessária à emancipação dos homens.

\section{Os sinais da regulação no SINAES}

Das experiências vivenciadas nas últimas décadas no século XX na área da avaliação educacional, ressaltamos marcos históricos que se projetaram nos cenários das Instituições de Educação Superior de forma cíclica e alternada. Tais feitos se constituíram por iniciativas de coletivos que impulsionaram a elaboração de políticas públicas multifacetadas, compostas por ordem e domínio, bem como por ações de âmbito emancipatório. Trata-se das concepções regulatória e formativa da avaliação em luta por seus espaços e por suas ações no cotidiano acadêmico.

Na avaliação sob o enfoque regulatório, os privilégios recaem no âmbito da lógica de controle e da gestão burocrática. O principal foco desta concepção se constitui no regramento e na legalidade como fontes de disciplina e disponibilidade para inculcação de valores estabelecidos pelo Estado. Neste modelo, o domínio se faz entre os sistemas educacionais, de ensino e escolar que se mostram refletidos pelos princípios do sistema capitalista em sua essência individualista, concorrencial e meritocrática. O mérito surge na figura de recompensa pelos objetivos alcançados diante da concepção valorada pelos preceitos neoliberais difundidos pela globalização.

Libâneo (2013) menciona em seus estudos sobre processos de organização e gestão, duas concepções díspares que se estabelecem frente às finalidades sociais e políticas da educação, são elas: a científica-racional e a sociocrítica. Na primeira, os seus elementos se mostram baseados no paradigma objetivista (FRANCO, 1991) aproximando-se do caráter regulatório da avaliação. Assim, na concepção científica-racional, há a predominância da burocracia, em meio às exigências presentes nas funções e cargos hierarquizados da instituição de ensino e do sistema educacional. Seu contexto embebecido de realidade neutra apresenta gestão centralizada e focada em índices de eficácia e eficiência como resultados institucionais.

Já na concepção sociocrítica, sua essência dialoga com os aspectos referenciados nos valores do paradigma indivíduo-sociedade (FRANCO, 1991), que por sua vez se vincula aos aspectos fundantes da avaliação formativa.

A avaliação formativa se caracteriza como um processo em que a participação coletiva e integrada se realiza visando a conscientização dos valores históricos, sociais, políticos, econômicos e culturais, enquanto elementos contraditórios e deflagradores da transformação social. Assim, a participação efetiva e a autonomia dos atores sociais nas discussões sobre temas sociais se tornam fundamentais para que o equilíbrio de forças 
heterogêneas faça parte do processo democrático (BELLONI, 2000; DIAS SOBRINHO, 2005; ANDRIOLA, 2005 e SORDI; LUDKE, 2009).

Diante destas variantes conceituais, temos o processo de avaliação que se ocupa da apreciação multifacetada das Instituições de Ensino, seja nos níveis básico ou superior, denominada avaliação institucional. Esta avaliação destinada à tratativa de programas, planos e projetos dispõe-se ao estudo, operacionalização e gestão de processos junto aos sistemas educacionais.

Saviani (2017) caracteriza o sistema educacional como produto da educação sistematizada. Afirma ainda, que o homem é capaz de educar sistematicamente, quando toma consciência da estrutura educacional, captando seus problemas e refletindo sobre eles. Ao problematizar os incômodos questionamentos presentes neste sistema, cria objetivos que possam ser alcançados em meio ao contexto dialético da ação-reflexão-ação.

Neste movimento em que a dialética se mostra privilegiada, a avaliação das instituições pode se apresentar como mais um instrumento de apreensão e poder por parte do Estado. Tal apropriação se materializa por meio da regulação amparada nas legislações que passam a empreender o caminho a ser trilhado pela IES. O contraponto desta questão se assenta na participação dos sujeitos que comprometidos e conscientes com a gestão democrática podem eleger o coletivo acadêmico e cumprir o seu papel social.

Dentre as experiências brasileiras vivenciadas no campo da avaliação institucional ao longo do século $\mathrm{XX}$, destacamos as principais políticas públicas de avaliação da Educação Superior que nutriram a sociedade, dando moldes à prática avaliativa atual, no marco do ano 2020.

As iniciativas avaliativas constituídas com predominância formativa foram: o Programa de Avaliação da Reforma Universitária (PARU) (1983) e o Programa de Avaliação Institucional das Universidades Brasileiras (PAIUB) (1993). Já as políticas consolidadas por aspectos regulatórios foram: a Comissão Nacional para Reformulação da Educação Superior (CNRES) (1985); o Grupo Executivo para a Reformulação da Educação Superior (GERES) (1986); o Exame Nacional de Cursos (ENC) (1995) e a Análise das Condições de Oferta (ACO) (1996) (BARREIROS; ROTHEN, 2008).

Podemos perceber que as forças regulatória e formativa se alternaram em ciclos temporais, ora prevalecendo uma em relação à outra, possivelmente implicadas pelos impactos de suas ações no seio das instituições de ensino. Destas experiências, surgiu o SINAES por meio da Lei $n^{\circ}$ 10.861, de 14 de abril de 2004 (BRASIL, 2004) em vigor no ano de 2020.

O SINAES foi concebido de forma híbrida em meio às articulações dos defensores das concepções regulatória e formativa. Entretanto, os efeitos práticos nas IES foram se consolidando sob o ordenamento de ações predominantemente da legalidade e da instrumentalidade, cotejados pela premiação e punição, tão contestadas pelos defensores da avaliação formativa. 


\section{A trilha do instrumento de avaliação institucional externa}

A Lei $n^{\circ}$ 10.861/2004 (BRASIL, 2004) surge com o objetivo de assegurar o processo de avaliação das instituições de educação superior do país, incluindo seus cursos de graduação e o desempenho acadêmico dos estudantes.

O SINAES produziu ao seu redor uma série de procedimentos para sua implementação, dentre eles a criação da Comissão Nacional de Avaliação da Educação Superior (CONAES) responsável por coordenar e supervisionar o SINAES. Além disto, possui a incumbência de estabelecer a institucionalização da autoavaliação institucional nas IES, coordenada pelas Comissões Próprias de Avaliação - CPAs e da avaliação externa a ser conduzida por equipes designadas pelo Instituto Nacional de Estudos e Pesquisas Educacionais Anísio Teixeira (Inep), órgão do Ministério da Educação (MEC).

Uma das primeiras medidas da CONAES foi a elaboração do Roteiro de Auto-avaliação (2004a) com orientações gerais às CPAs das Instituições de Educação Superior. Neste documento foram expressos os encaminhamentos para que as diretrizes do SINAES fossem cumpridas. Dentre elas, a organização e formação das comissões autônomas nas IES, buscando uma organicidade na avaliação. Cabe destacar que algumas instituições de ensino já possuíam alguns grupos acadêmicos formados em torno da avaliação, tendo em vista as experiências avaliativas como o PARU, seguidas de outras políticas, em especial do PAIUB (SOUZA, 2002). Este programa proporcionou e deflagrou diversas ações mediadas pelas concepções sociocrítica e formativa. Na contramão destes encaminhamentos, houve também reações de coletivos acadêmicos que articulados à concepção técnico-científica apoiaram o Estado em suas políticas regulatórias.

O Roteiro de Auto-avaliação (2004a) explicitou para as IES a seguinte organicidade do SINAES: a Avaliação das Instituições de Educação Superior (Avalies) desenvolvida nos processos da autoavaliação interna coordenada pela Comissão Própria de Avaliação (CPA) de cada IES e da avaliação externa conduzida por comissões designadas pelo Inep; a Avaliação dos Cursos de Graduação (ACG) mediada por instrumentos, procedimentos e visitação de comissões externas junto às IES; e por fim, a Avaliação do Desempenho dos Estudantes, realizada pelo INEP como mecanismo de aferição da qualidade do ensino (Exame Nacional de Avaliação de Desempenho dos Estudantes - Enade).

O SINAES definiu dez dimensões para que os processos avaliativos fossem realizados, contemplando a identificação do perfil da IES, bem como o significado de sua atuação. As dimensões do SINAES foram assim elencadas: I- missão e o plano de desenvolvimento institucional; II- política para o ensino, a pesquisa, a pós-graduação e a extensão; IIIresponsabilidade social da instituição; IV- comunicação com a sociedade; V- políticas de pessoal, carreiras do corpo docente e do corpo técnico-administrativo; VI- organização e gestão da instituição; VII- infraestrutura física; VIII- planejamento e avaliação, especialmente a autoavaliação; IX- políticas de atendimento aos estudantes; e Xsustentabilidade financeira (BRASIL, 2004). 
Observamos que até então, os indicadores de avaliação da educação superior têm priorizado em tese a atividade-fim das instituições de educação superior, considerando as políticas acadêmicas de ensino, pesquisa extensão e corpo discente, apesar dos desafios mercadológicos do ensino do século XXI.

Na Portaria n. 40/2007 republicada em 2010 (BRASIL, 2010) tais elementos se materializam em marcadores de produção, vinculada à produtividade da IES e referenciada por indicadores de avaliação e por instrumentos definidos pela CONAES.

Neste processo foram definidos ciclos avaliativos, que se constituem na ação avaliativa periódica de Instituições de Educação Superior, bem como de seus respectivos cursos. Estas avaliações são cadenciadas pelas avaliações trienais de desempenho de estudantes (Enade), que por sua vez subsidiam o recredenciamento e renovação de reconhecimento das IES. Para tanto, os indicadores de qualidade criados pelo MEC ao serem implementados nas avaliações in loco, resultam em conceitos que no âmbito da IES, denomina-se Conceito Institucional (CI). O CI decorre da apreciação das dez dimensões definidas pelo SINAES graduado em cinco níveis, de 1 (um) a 5 (cinco). O referencial de qualidade satisfatória se aplica quando os valores obtidos são iguais ou superiores a 3 (três).

Já quando os indicadores de qualidade são aplicados na avaliação dos cursos superiores, também por comissões constituídas pelo INEP, os conceitos então gerados são identificados como Conceito de Curso (CC).

O Inep idealizou um composto metodológico de indicadores de qualidade, cuja base se ampara nos referenciais gerados pelo Enade, somados a outros aspectos instrumentais da base de dados do MEC.

Ainda segundo a Portaria no. 40/2007 republicada em 2010 (BRASIL, 2010), os indicadores de qualidade são constituídos no âmbito dos cursos superiores com a denominação de Conceito Preliminar de Curso (CPC); na esfera da IES o referencial é o Índice Geral de Cursos Avaliados da Instituição (IGC); e por fim, quando direcionado ao desempenho de estudantes, o conceito passa a se constituir por meio dos resultados do Enade.

Apesar da CONAES ressaltar desde as suas orientações iniciais em 2004 que o centro de referência e articulação do sistema de avaliação seria o Avalies, com a participação efetiva da autoavaliação interna, os anos seguintes demonstraram o contrário. O que observamos foi a promoção do protagonismo do Enade (GRIBOSKI, 2014) e a ênfase na regulação por parte do Estado, incentivando um desequilíbrio na avaliação da educação superior e contribuindo para o desprestígio das ações avaliativas colegiadas e democráticas.

Tal fenômeno foi tratado como "Enade ampliado" (SOUSA E FERNANDES, 2015) tendo em vista a supervalorização do Enade, principalmente a partir da consolidação de índices definidos na Portaria Normativa $n^{\circ}$ 40, de 12 de dezembro de 2007 (BRASIL, 2007) e intensificada com sua republicação em 2010. 
Deste modo, atendendo à lógica burocrática e de controle, assim como uma suposta autonomia defendida às Instituições de Educação Superior na legislação do SINAES, a CONAES tem criado e atualizado instrumentos que possibilitam à luz da regulação identificar os níveis de qualidade apresentados nas IES e em seus cursos.

Assim sendo, o SINAES após dez anos de sua criação tendo como referência as 10 dimensões já mencionadas sofreu alterações por meio da Nota Técnica no 14 /2014 INEP/MEC (BRASIL, 2014). O INEP aglutinou as dez dimensões em cinco eixos, tendo como justificativa a otimização do processo avaliativo, foram eles: Eixo 1 - Planejamento e Avaliação Institucional; Eixo 2 - Desenvolvimento Institucional; Eixo 3- Políticas Acadêmicas; Eixo 4 - Políticas de Gestão; Eixo 5 - Infraestrutura Física.

Quadro 1-Pesos dos eixos para os atos de recredenciamento e credenciamento nas
modalidades presencial e a distância presentes nos Instrumentos de Avaliação
Externa (BRASIL, INEP/MEC, 2014a) e (BRASIL, INEP/MEC, 2017b)

\begin{tabular}{|c|c|c|c|c|}
\hline \multirow[t]{2}{*}{ EIXOS do SINAES } & \multicolumn{2}{|c|}{$\begin{array}{l}\text { Instrumento Recredenciamento e } \\
\text { Credenciamento para Mudança de } \\
\text { Organização Administrativa } \\
\text { (Peso dos eixos) }\end{array}$} & \multicolumn{2}{|c|}{ Número de indicadores por eixo } \\
\hline & INEP/MEC, 2014 & INEP/MEC, 2017 & INEP/MEC, 2014 & INEP/MEC, 2017 \\
\hline $\begin{array}{l}\text { 1. Planejamento e Avaliação } \\
\text { Institucional }\end{array}$ & 10 & 10 & 5 & 5 \\
\hline 2. Desenvolvimento Institucional & 20 & 30 & 9 & 7 \\
\hline 3. Políticas Acadêmicas & 30 & 10 & 13 & 12 \\
\hline 4. Políticas de Gestão & 20 & 20 & 8 & 8 \\
\hline 5. Infraestrutura & 20 & 30 & 16 & 18 \\
\hline TOTAL & 100 & 100 & 51 & 50 \\
\hline
\end{tabular}

Fonte: Elaboração própria com base nas Notas Técnicas no 14 /2014 e nº 16/2017-CGACGIES/DAES/INEP/MEC (BRASIL, 2014, 2017a)

Somada a esta nova estruturação, surgiu mais uma significativa mudança no SINAES, intensificando a concepção regulatória e burocrática da avaliação em sua constituição. Trata-se dos pesos atribuídos aos indicadores aprovados em extratos do Instrumento de Avaliação Institucional Externa Presencial e a Distância que subsidia os atos de Recredenciamento e Transformação de Organização Acadêmica das IES (2017) modificado pela Portaria no 1.382, de 31 de outubro de 2017 (BRASIL, 2017). No Quadro 1, observamos a nova disposição dos pesos em relação ao Instrumento anterior.

Ao considerarmos as ações neoliberais e as práticas de regulação e meritocracia que compõem a sua essência, observamos o reforço da prática do Estado Avaliador (NEAVE, 
2001) conferindo um desvio da função social do Estado ao apresentar uma proposta de avaliação da educação superior focada em critérios técnicos e nas atividades-meio das IES. Neste referencial estatal, o que se assevera como relevante na avaliação são as produções eficientes e seus resultados, presentes na concepção burocrática e de controle e não no processo inerente ao papel social da educação, baseado na concepção sociocrítica.

Dentre as mudanças reveladas no quadro 1 (um) nossa apreciação recaiu sobre o eixo 3 (três) devido aos possíveis impactos na missão e valores das Instituições de Educação Superior. Assim, analisando o eixo 3 (três) referente às Políticas Acadêmicas que por sua vez, abrangem as dimensões 2 (dois) (Políticas para o Ensino, Pesquisa e Extensão), 4 (quatro)(Comunicação com a Sociedade) e 9 (nove)(Políticas de Atendimento aos Discentes) do SINAES, observamos que seu peso foi diminuído, de 30 para 10 na avaliação de recredenciamento institucional do MEC. Com esta ação as atividades de ensino, pesquisa e extensão se mostraram desprestigiadas, afetando os princípios e a razão de ser das IES, em especial da Universidade e do Instituto Federal considerando este tripé universal.

Tal mudança demostra mais um retrocesso à Educação Superior, maculando a autonomia universitária, desprestigiando o trabalho docente e a função social da educação. Neste particular, Mancebo (2004) em estudo sistemático delimitado no período de 1990 a 2000 já apresentava os principais efeitos da globalização no trabalho docente, interferindo diretamente em seus aspectos fundantes: a ênfase na valorização das ações de eficiência, a racionalização de custos e da gestão, o controle e supervisão da produtividade acadêmica, a flexibilização dos processos de trabalho, a polivalência nas atividades do magistério e as medidas privatistas na educação.

Observamos com isto, que mesmo diante dos esforços da comunidade acadêmica ao longo dos anos em prol da valorização da educação no âmbito emancipatório, o Estado segue impondo elementos burocráticos e de controle por meio da regulação, em detrimento da avaliação na perspectiva formativa.

O papel do discente na avaliação também se reportou a um segundo plano, uma vez que suas atividades ficaram reduzidas a dois indicadores de um total de 12 dispostos na dimensão 3 (três) políticas acadêmicas, foram eles: política de atendimento aos discentes e políticas institucionais e ações de estímulo à produção discente e participação em eventos (graduação e pós-graduação).

As instituições de educação superior públicas historicamente apresentam uma avaliação favorável nestas dimensões acadêmicas, entretanto, politicamente com a perda de força deste elemento, o foco da regulação passou a ser o eixo 2 (dois) que aborda o Desenvolvimento Institucional e o eixo 5 (cinco) referente à Infraestrutura. Ambos tiveram aumento de peso, de 20 para 30, destacando-se dos demais eixos.

Assim, nesta perspectiva do SINAES, o ponto central da avaliação das IES passou a ter uma intensificação ainda maior nos aspectos da produtividade, da racionalidade técnica e 
da burocracia, em detrimento da função social da educação, referenciadas nas atividades acadêmicas (ensino, pesquisa, extensão, assistência estudantil e a gestão destas frentes).

Dias Sobrinho (2011) corrobora nesta abordagem ao afirmar que,

\begin{abstract}
A 'qualidade' da educação está em grande parte (talvez ainda) sob a égide dos Estados que tem o dever de regular e supervisionar o cumprimento dos requisitos que devem ser atendidos, mas incorpora e emula a mesma lógica competitiva que impera na economia. [...] Muitas vezes os índices tomam os lugares da própria qualidade. Para o público em geral, o que parece ser o definidor por essência da qualidade educativa nos processos de acreditação e avaliação praticados por governos e agências, na perspectiva da economia de mercado aqui criticada, se reduz à demonstração mensurável de desempenhos e resultados de titulação de profissionais, aos rendimentos estudantis, aos números de publicações e citações, às condições de infra-estrutura física e outros elementos que possam ser objetivamente quantificados (DIAS SOBRINHO, 2011, p. 27).
\end{abstract}

O contexto pontuado pelo autor acompanha a ênfase na regulação provida pelo INEP/MEC, tanto na avaliação de cursos de graduação e resultados do Enade, quanto na política de avaliação da pós-graduação no Brasil desempenhada pela CAPES, em que o rigor e a qualidade acadêmica e social do ensino, da pesquisa e da extensão são considerados metricamente (BRASIL, 2017c). Além disto, nesta nova configuração do Instrumento de Avaliação Externa, devemos considerar a representatividade que o Enade alcança nas recentes métricas, tendo em vista a perda dos pesos no eixo das políticas acadêmicas, direcionadas aos estudantes.

O aspecto mais grave a denunciar é o desvio do foco da razão de ser da educação superior, em que o objetivo deve ser a formação humana e para o mundo do trabalho, de modo que o educando seja capaz de intervir criticamente na sociedade e transformá-la.

\title{
Os Institutos Federais nos novos moldes da regulação do SINAES
}

Os IFs instituídos pela Lei n 11.892 em 29 de dezembro de 2008 (BRASIL, 2008) são uma política resultante das ações moventes da educação profissional no Brasil, bem como da revitalização e expansão da Rede Federal de Educação Profissional e Tecnológica.

Os IFs são definidos em lei como instituição de educação superior, básica e profissional, pluricurricular e multicampi, com especialização na oferta de educação profissional e tecnológica nas diferentes modalidades de ensino revelaram-se como organização acadêmica híbrida e com distintas identidades. Tais características foram herdadas em especial das instituições que Ihes deram origem, foram elas: as Escolas Técnicas Federais, as Escolas Agrotécnicas Federais, as Escolas Técnicas vinculadas às Universidades Federais e os Centros Federais de Educação Tecnológica.

A associação destas distintas instituições proporcionou aos IFs a apropriação de riquezas de culturas, identidades e experiências institucionais que contribuíram para amenizar os desafios ao cumprimento das legislações da educação superior, como o SINAES (PAIVA, 2012, 2018). 
Dentre as implicações orgânicas impostas ao Instituto Federal, destacamos a sua equivalência às universidades federais, conforme disposto no art. $2^{\circ}$. da Lei $n^{\circ} 11.892 / 2008$ (BRASIL). Tal fato exigiu dos IFs a prática da verticalização do ensino, bem como dos demais processos pedagógicos, administrativos e de gestão, tornando a avaliação institucional, referenciada no SINAES um processo em constante adaptação, frente aos instrumentos avaliativos do INEP/MEC.

Saviani (2017, p.8) em um de seus estudos, destaca: "O produto intencional e concreto de uma práxis intencional coletiva, eis o que está sendo denominado 'sistema'". Como vimos, o SINAES apresentou-se ao longo de sua história como um organismo cerceado de concepções, ora formativa, ora enfaticamente regulatória. Estas características se sobressaem diante de uma instituição híbrida como os IFs que ainda estão em processo de construção identitária e sob as influências dos paradigmas decorrentes das suas instituições de origem.

A entrada dos IFs em 2008 no cenário das organizações acadêmicas contribui ao questionamento sobre os critérios, indicadores e pesos definidos no SINAES ao pretender representar a totalidade das Instituições de Educação Superior, sem macular suas identidades, culturas e papéis sociais.

Após 2017 em decorrência de crises econômicas e políticas no Brasil, os recursos investidos nos IFs de forma a atender aos objetivos propostos em lei, diminuíram paulatinamente até cessar com severos cortes em 2019, principalmente no que concerne à cifra de investimento de custeio às Instituições Federais, afetando a infraestrutura e demais indicadores dispostos nos cinco eixos do SINAES. Com isto, no médio e longo prazo, os IFs, principalmente os que se encontravam em expansão de cursos e campi poderão ter dificuldades para atingir estes indicadores com excelência, tendo em vista a precarização do trabalho decorrente da verticalização do ensino, dentre outras singularidades da instituição.

Considerando que os eixos de desenvolvimento institucional e infraestrutura, juntos, passaram a ter peso 60 na avaliação do processo de renovação de recredenciamento do MEC, o impacto se mostra uma ameaça para o futuro destas Instituições.

Outro aspecto a ser considerado é o conceito de desenvolvimento institucional proposto em 2019 nos projetos do MEC postos em discussão pelas comunidades acadêmicas. Nestas proposições a instituição pública passa a ter uma visão expressa de empreendedorismo e geração de receita, bem como a vincular tais ações ao desempenho acadêmico de forma meritocrática, influindo diretamente na avaliação institucional interna e externa.

Esta crise paradigmática que se anuncia provavelmente repercutirá negativamente nos IFs, pois segundo dados do INEP/MEC do total de 38 IFs no Brasil, 12 deles obtiveram conceito institucional 3 (três), estando no limite mínimo do recredenciamento; 24 IFs receberam o conceito institucional 4 (quatro) e apenas 02 (dois) IFs possuem o conceito institucional 5 (cinco), considerando o primeiro semestre de 2020. 
Do total de 38 IFs, um deles foi avaliado em 2012 conduzido pelo Instrumento vigente na Nota Técnica de 9 de fevereiro de 2011; 18 IFs foram avaliados no período de 20152016 no âmbito da Nota Técnica 14 de 2014. Outros 14 IFs foram avaliados em 2017 na transição dos dois Instrumentos, mas ainda na vigência do instrumento previsto na Nota Técnica 14 de 2014.

Desta totalidade, apenas 5 (cinco) IFs foram avaliados na vigência do Instrumento sob a gerência da Portaria n 1.382 , de 31 de outubro de 2017 do MEC/INEP implementado a partir de 2018, foco de crítica deste artigo (BRASIL, 2020).

Assim, apresentamos no quadro 2 (dois) a disposição destas cinco instituições, seguida do ano em que foram avaliadas e do conceito atribuído pelo INEP/MEC.

\begin{tabular}{|c|c|c|}
\hline INSTITUTO FEDERAL & $\begin{array}{c}\text { ANO DA } \\
\text { AVALIAÇÃO }\end{array}$ & $\begin{array}{l}\text { CONCEITO } \\
\text { INSTITUCIONAL }\end{array}$ \\
\hline Instituto Federal da Paraíba - IFPB & 2018 & 4 \\
\hline Instituto Federal de Goiás- IFG & 2019 & 4 \\
\hline Instituto Federal do Ceará - IFC & 2018 & 5 \\
\hline Instituto Federal do Pará- IFPA & 2018 & 4 \\
\hline Instituto Federal do Sudeste de MG - IFSEMG & 2018 & 3 \\
\hline
\end{tabular}

Diante dos dados observados, ao analisarmos os resultados do conceito institucional dos IFs no Brasil devemos então relativizar o momento e o instrumento legal pelos quais a instituição foi avaliada. Isto porque, devido à diferença entre os critérios, indicadores e pesos contidos nos distintos Instrumentos de Avaliação Externa ao longo do tempo, provavelmente os resultados expressaram conceitos que devem ser avaliados considerando as variantes identificadas.

Tal fato contraria por si só as métricas quantitativas presentes no paradigma objetivista e na concepção técnico-científica, presentes na regulação estatal comprometida com a meritocracia posta em prática nas políticas públicas educacionais. Quiçá frente às concepções formativa e sociocrítica que valorizam a coletividade em suas singularidades, histórias, identidades e limites. 


\section{Conclusão}

Os instrumentos de controle no Brasil estabelecidos pelo Estado no âmbito da avaliação institucional têm acompanhado a lógica do sistema capitalista em seus valores calcados na máxima da eficiência, da eficácia e do paradigma objetivista inculcado na comunidade acadêmica pela burocracia estatal.

O Instrumento de Avaliação Externa gerido pelo Instituto Nacional de Estudos e Pesquisas Educacionais Anísio Teixeira (Inep) e amparado legalmente pelo SINAES pode se caracterizar como um paradigma de padrões que as Instituições de Educação Superior devem seguir, pois caso contrário, não estariam cumprindo o papel definido pelo Estado Avaliador. Deste modo, os instrumentos de controle no Brasil estabelecidos pelo Estado têm acompanhado a lógica do sistema capitalista e suas implicações produtivistas na educação.

Observamos as constantes mudanças registradas na história das principais políticas públicas da avaliação da Educação Superior, em especial as alternâncias entre as concepções formativa e regulatória, com reflexos no cotidiano e no papel social das IES.

As dez dimensões do SINAES distribuídas em cinco eixos, tiveram os pesos dos indicadores modificados, interferindo, sobremaneira, na institucionalidade das IES. Ao diminuir os pesos do eixo 3 (três) referente às Políticas Acadêmicas de 30 para 10, o SINAES, representante do Estado, pôs em evidência a não valorização da atividade-fim da Universidade e do Instituto Federal que se mediados pela concepção sociocrítica, destinam-se à formação humana e profissional, favorecendo o desenvolvimento do senso democrático, tão vital à convivência social. Em seu lugar, o SINAES passou a prestigiar desproporcionalmente o eixo 2 (dois) que trata do Desenvolvimento Institucional e o eixo 5 (cinco) direcionado à Infraestrutura, tendo o aumento nos seus respectivos pesos de 20 para 30. Como resultado imediato, observamos nos IFs analisados a intensificação de planejamentos estratégicos postos em prática na gestão e no trabalho docente que impulsionam a meritocracia, a competitividade e o empreendedorismo nos processos institucionais.

Cabe ressaltar a importância de todos os eixos estruturados no SINAES para que a IES possa ser avaliada com equilíbrio, fazendo uso das forças democráticas da autoavaliação institucional formativa e da avaliação externa. Contudo, a nossa crítica e denúncia recaem sobre o esvaziamento das Universidades e IFs

, que diante destas mudanças desviam-se de sua missão social, focada na qualidade das atividades pedagógicas, administrativas e de gestão.

Além disto, diante de critérios diferenciados adotados nos diversos instrumentos em períodos distintos, os resultados dos Conceitos Institucionais tornam-se duvidosos, tendo em vista a impossibilidade de associar pesos díspares aos eixos dispostos no SINAES.

Para além das margens numéricas dos conceitos definidos e remetidos às IES pelo INEP, faz-se necessário a revisão das políticas públicas e da concepção de educação que se 
impõe à sociedade. Neste cenário, a premiação e a punição são requisitos que classificam e definem o lugar que as IES devem ocupar na organização acadêmica, gerida por índices e métricas, induzindo assim, a qualidade mercadológica.

Percebemos nas idas e vindas dos Instrumentos e procedimentos avaliativos do SINAES que a lógica positivista, mercadológica e burocrática ainda se perpetua, pois a avaliação institucional, assim significada, exige da comunidade acadêmica e das demais esferas da sociedade a denúncia. Seguimos firmes no propósito da educação e da prática da avaliação formativa, referenciada na concepção sociocrítica.

\section{Referências}

ANDRIOLA. Desafios e necessidades que se apresentam às (CPAs) das (IES), visando à implementação do (SINAES). In: RISTOFF, Dilvo; ALMEIDA Jr. Vicente de Paula (Orgs.). Avaliação participativa: perspectivas e desafios. Brasília: INEP, 2005.

BARREIROS, Gladys Beatriz. ROTHEN, José Carlos. Para uma história da avaliação da Educação Superior Brasileira: análise dos documentos do Paru, Cnres, Geres e Paib. Avaliação, Campinas; Sorocaba, SP, v. 13, n. 1, p. 131-152, mar. 2008.

BELLONI, Isaura. A Função Social da Avaliação Institucional. In DIAS SOBRINHO, José; RISTOFF, Dilvo. Ilvo. (orgs). Universidade desconstruída- avaliação institucional e resistência. Florianópolis: Insular, 2000.

BRASIL. Lei n 10.861, de 14 de abril de 2004. Institui o Sistema Nacional de Avaliação da Educação Superior - SINAES e dá outras providências. Diário Oficial [da] República Federativa do Brasil, Poder Executivo, Brasília, DF, Seção 1, p.3, 15 abr.de 2004.

BRASIL. Ministério da Educação. INEP. Sistema Nacional de Avaliação da Educação Superior (SINAES) Roteiro de Auto- Avaliação Institucional. Brasília: 2004a.

BRASIL. Decreto n 5.773, de 9 de maio de 2006. Dispõe sobre o exercício das funções de regulação, supervisão e avaliação de instituições de educação superior e cursos superiores de graduação e seqüenciais no sistema federal de ensino. Diário Oficial [da] República Federativa do Brasil, Brasília, DF, Seção 1, p. 6, 10 mai. 2006.

BRASIL. Ministério da Educação. Portaria Normativa n 40, de 12 de dezembro de 2007 (BRASIL, 2007). Institui o e-MEC, sistema eletrônico de fluxo de trabalho e gerenciamento de informações relativas aos processos de regulação da educação superior no sistema federal de educação. Diário Oficial [da] República Federativa do Brasil, Brasília, DF, n. ${ }^{\circ}$ 239, de 13.12.2007, Seção 1, página 39/43. 
BRASIL. Lei no 11.892, de 29 de dezembro de 2008. Institui a Rede Federal de Educação Profissional Científica e Tecnológica e dá outras providências. Diário Oficial [da] República Federativa do Brasil, Brasília, DF, Seção 1, p. 1, 30 dez. 2008.

BRASIL. Ministério da Educação. Portaria n 40, de 12 de dezembro de 2007 (republicada em 2010). Institui o e-MEC, sistema eletrônico de fluxo de trabalho e gerenciamento de informações relativas aos processos de regulação, avaliação e supervisão da educação superior no sistema federal de educação, e o Cadastro e-MEC de Instituições e Cursos Superiores e consolida disposições sobre indicadores de qualidade, banco de avaliadores (Basis) e o Exame Nacional de Desempenho de Estudantes (ENADE) e outras disposições. Diário Oficial [da] República Federativa do Brasil, Brasília, DF, n. ${ }^{\circ} 249$, Seção 1, quartafeira, 29 de dezembro de 2010, páginas 23/3, 2010.

BRASIL. Ministério da Educação. Nota Técnica n 9/2011/CGACGIES/DAES. Avaliação de cursos e instituições no ciclo avaliativo, como referencial para os processos de renovação de reconhecimento e recredenciamento do sistema nacional de avaliação da educação superior - SINAES. 2011.

BRASIL. Ministério da Educação. Nota Técnica nº. 014/2014- CGACGIES/DAES/INEP/MEC. Instrumento de Avaliação Institucional Externa do Sistema Nacional de Avaliação da Educação Superior (SINAES), 2014.

BRASIL. Ministério da Educação. INEP. SINAES, CONAES, DAES. Instrumento de Avaliação Institucional Externa. Subsidia os atos de credenciamento, recredenciamento e transformação da organização acadêmica (presencial). Brasília, agosto de 2014a.

BRASIL. Ministério da Educação. Portaria no 23, de 20 de dezembro de 2016. Altera dispositivos da Portaria Normativa MEC $n^{\circ}$ 40, de 12 de dezembro de 2007, republicada em 2010, para efeitos imediatos nos processos de cálculo e divulgação dos Indicadores de Qualidade da Educação Superior, a partir da edição de 2015. Diário Oficial [da] República Federativa do Brasil, Brasília, DF, n. ${ }^{\circ}$ 244, Seção 1, p. 75, 2016.

BRASIL. Portaria $\mathrm{n}^{\circ}$ 1.382, de 31 de outubro de 2017. Aprova, em extratos, os indicadores dos Instrumentos de Avaliação Institucional Externa para os atos de credenciamento, recredenciamento e transformação de organização acadêmica nas modalidades presencial e a distância do Sistema Nacional de Avaliação da Educação Superior - SINAES. Diário Oficial [da] República Federativa do Brasil, de 01/11/2017 n² 210, Seção 1, p.. 14.

BRASIL. Ministério da Educação. Nota Técnica no 16/2017/CGACGIES/DAES. Novos instrumentos de avaliação externa: instrumento de avaliação institucional externa Presencial e a distância (IAIE); instrumento de avaliação de cursos de graduação - presencial e a distância (IACG). 2017 a. 
BRASIL. Ministério da Educação. INEP. SINAES, CONAES, DAES. Instrumento de Avaliação Institucional Externa Presencial e a Distância Transformação de Organização Acadêmica, 2017. Diretoria de Avaliação da Educação Superior | Daes, Brasília, DF, 2017b.

BRASIL. Decreto n 9.235/2017, de 15 de Dezembro de 2017c. Dispõe sobre o exercício das funções de regulação, supervisão e avaliação das instituições de educação superior e dos cursos superiores de graduação e de pós-graduação no sistema federal de ensino. Diário Oficial [da] República Federativa do Brasil,- Seção 1 - 18/12/2017, p. 2 (Publicação Original). 2017c.

BRASIL. Ministério da Educação, INEP, e-MEC. Cadastro Nacional de Cursos e Instituições de Educação Superior. Cadastro e-MEC, 2020. Disponível em: http://emec.mec.gov.br/>. Acesso em: 14 mar. 2020.

BELLONI, Isaura; MAGALHÃES, Heitor de; SOUSA, Luzia C. de. Metodologia de Avaliação em Políticas Públicas: uma experiência em educação profissional. $4^{a}$. ed. São Paulo; Cortez, 2007. (Coleções Questão de nossa Época; v. 75).

DIAS SOBRINHO, José. Avaliação como instrumento da formação cidadã e do desenvolvimento da sociedade democrática: por uma ético - epistemologia da avaliação. In: RISTOFF, Dilvo; ALMEIDA Jr. Vicente de Paula (orgs.). Avaliação participativa: perspectivas e desafios. Brasília: INEP, 2005.

DIAS SOBRINHO, José. Qualidade e garantia de qualidade: acreditação da educação superior. ROTHEN, José Carlos; BARREIROS, Gladys Beatriz (org.), In: Avaliação da educação: diferentes abordagens críticas. São Paulo: Xamã, 2011, p. 17-41.

FRANCO, Maria Laura P. Barbosa. Pressupostos epistemológicos da avaliação educacional. In: SOUSA, Clarilza Prado de (org.). Avaliação do rendimento escolar. São Paulo: Papirus, 1991, p. 13-26.

GAMBOA, Sílvio Sánchez. Epistemologia da Pesquisa em Educação. $2^{\mathrm{a}}$. reimpressão. Campinas, SP: Praxis. 1998.

GRAMSCI, Antonio. Os intelectuais e a organização da cultura. $6^{a}$. ed., Rio de Janeiro: Civilização Brasileira, 1988.

GRIBOSKI, Claudia Maffini. Regular e/ou induzir qualidade? Os cursos de pedagogia nos ciclos avaliativos do SINAES. 2014. 482 f. (Tese de Doutorado) - Programa de PósGraduação em Educação - PPGE, Faculdade de Educação - FE., Universidade de Brasília UnB, Brasília, 2014.

MINAYO, Maria Cecilia de Souza (org.); DESLANDES, Suely Ferreira; GOMES, CRUZ NETO, Otávio; GOMES, Romeu. Pesquisa Social: teoria, método e criatividade. 27. ed. Petrópolis, RJ: Vozes, 2008. 
NEAVE, Guy. Educación superior: historia y política. Barcelona: Gedisa, 2001.

KUHN, Thomas S. A estrutura das revoluções científicas. Editora Perspectiva. Coleção Debates. Tradutores: Beatriz Vianna Boeira e Nelson Boeira; Revisão: Alice Kyoto Miyashiro; Produção: Ricardo W. Neves e Adriana Garcia. Título do original inglês: The Structure of Scientific Revolutions Copyright (C) 1962, 1970 by The University of Chicago. $4^{a}$.ed. São Paulo: Editora Perspectiva S. A., 1998.

LIBÂNEO, José Carlos. Organização e gestão da escola: teoria e prática. 6. ed. ver. amp., São Paulo: Heccus Editora, 2013.

MANCEBO, Deise. Uma análise da produção escrita sobre o trabalho docente em tempos de globalização. In: MANCEBO, Deise; FÁVERO, Maria de Lourdes de Albuquerque (orgs). Universidade: políticas, avaliação e trabalho docente. São Paulo: Cortez, 2004, p. 235-250.

SAVIANI, Demerval. Sistema Nacional de Educação e Plano Nacional de Educação: significado, controvérsias e perspectivas. Coleção Educação Contemporânea $2^{\mathrm{a}}$. ed. rev. e ampl. Campinas: São Paulo: Autores Associados, 2017.

SGUISSARDI, Valdemar. Regulação estatal versus cultura de avaliação institucional? Avaliação, Campinas; Sorocaba, SP, v. 13, n. 3, p. 857-862, nov. 2008.

SORDI, Maria Regina Lemes de; LUDKE, Menga. Da avaliação da aprendizagem à avaliação institucional: aprendizagens necessárias. Avaliação. Sorocaba, SP, 2009, v. 14, n. 2, p.324, julho, 2009.

SOUSA, José Vieira; FERNANDES, R. Ivanildo. SINAES ou NeoSINAES?: a avaliação da educação superior no Brasil à luz do Enade ampliado. Avalies. Simpósio Avaliação da Educação Superior., 17-18 de set. 2015. Universidade Federal do Rio Grande do Sul. Porto Alegre, RS, 2015, p. 1-16. Disponível em: http://www.ufrgs.br/avalies/anais-doevento/autores/artigos-1/145927 >. Acesso em: 14 mar. 2020.

SOUZA, Nádia Maria Pereira de. 0 estado da arte da avaliação da educação superior as diretrizes do MEC e a experiência de IES no Estado do Rio de Janeiro. 2002. 357 f. Tese (Doutorado em Ciências Sociais), Programa de Pós-Graduação em Desenvolvimento, Agricultura e Sociedade (CPDA), Universidade Federal Rural do Rio de Janeiro, Rio de Janeiro, 2002.

PAIVA, Liz Denize Carvalho. A Perspectiva da Autoavaliação Institucional e seus desafios no Instituto Federal de Educação, Ciência e Tecnologia do Rio de Janeiro. 2012. 136 f. Dissertação (Mestrado em Ciências) - Programa de Pós-Graduação em Educação Agrícola, PPGEA, Universidade Federal Rural do Rio de Janeiro, Seropédica, 2012.

PAIVA, Liz Denize Carvalho. Avaliação institucional e os desafios da avaliação formativa no Instituto Federal de Educação, Ciência e Tecnologia. 2018. 285 f. Tese (Doutorado 
em Educação) - Programa de Pós-Graduação em Educação, Contextos Contemporâneos e Demandas Populares, PPGEduc, Universidade Federal Rural do Rio de Janeiro, Seropédica, 2018.

\section{Informações sobre as autoras:}

\section{Liz Denize Carvalho Paiva}

Doutora em Educação pela Universidade Federal Rural do Rio de Janeiro (UFRRJ). Atua como Professora Adjunta na área de Planejamento, Avaliação e Gestão Educacional no Departamento de Teoria e Planejamento de Ensino do Instituto de Educação da UFRRJ onde integra o quadro de docentes colaboradores do Programa de Pós-Graduação em Educação Agrícola (PPGEA) e o quadro docente do Curso de Especialização Lato Sensu em Gestão Educacional (CEGEd). É membro da Rede UNIVERSITAS/BR de Pesquisadores, vinculada ao GT 11 - Ensino Superior e Política Educacional da Associação Nacional de Pesquisa e Pós-Graduação em Educação (ANPEd).

ORCID iD: http://orcid.org/0000-0003-4116-2674

E-mail: lizdepaiva@yahoo.com.br

\section{Nádia Maria Pereira de Souza}

Doutora em Ciências Sociais pela Universidade Federal Rural do Rio de Janeiro (UFRRJ). É aposentada como Professora Titular do Instituto de Educação da UFRRJ, onde integra o quadro docente do Programa de Pós-Graduação em Educação Agrícola (PPGEA). É Coordenadora da Disciplina de Prática de Ensino III - EAD do CEDERJ/UFRRJ; é membro do INEP/MEC/BASES; é membro da Rede UNIVERSITAS/BR de Pesquisadores; é membro associada da Associação Nacional pela Formação dos Profissionais da Educação (ANFOPE) e da Associação Nacional de Pesquisa e Pós-Graduação em Educação (ANPEd).

ORCID iD: http://orcid.org/0000-0002-6001-8275

E-mail:nmpsouza@uol.com.br

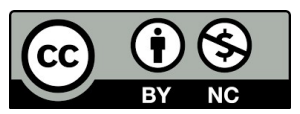

Esta obra está licenciada com uma Licença 